\title{
Current Patterns of Colorectal Carcinoma: Retrospective Evaluation of Cases
}

\author{
Tooba Irfan*, Amara Zafar, Muhammad Yusuf Hafiz \\ Dow Medical College, Karachi, Pakistan
}

\begin{abstract}
*Corresponding Author: Tooba Irfan, Dow Medical College, Karachi, Pakistan.Email: toobairfan.94@gmail.com
\end{abstract}
\begin{abstract}
Background: Colorectal carcinoma (CRC) is the most common malignancy affecting cecum, colon and rectum with a peak incidence in individuals between 60 to 70 years of age. It has been more common in male population than females and has a worldwide distribution, with the highest incidence in the developed countries. The prevalence of CRC is now growing in developing countries like Pakistan with an increasing incidence in younger population. The aim of the study was to determine the current patterns of colorectal carcinoma (CRC), its incidence, risk factors and the presenting complain of the people with CRC to Civil Hospital Karachi (CHK).

Methodology: This was a descriptive, retrospective, hospital-based study. A total of 121 patients were made part of the study who presented to the Oncology department in Civil Hospital Karachi during January 2012 to December 2014. Data was collected from the hospital files using a pre-formed questionnaire and was analyzed using Statistical Package for Social Sciences (SPSS version 20.0).

Results: A total of 121 patients were part of this study, out of them $65(53.7 \%)$ were males and $56(46.3 \%)$ were females. Most of the patients (43.0\%) in our study were more than 45 years old and $17.4 \%$ of the patients had a family history of CRC. Hematochezia was found to be the most common presenting complain amongst the patients. Constipation, abdominal pain and weight loss were other common presenting complains.

Conclusion: The increased incidence of CRC in younger population is an alarming situation however the peak incidence was still seen in patients above the age of 45 years. Males were seen to be affected more commonly than the females which were in consistence with the available literature. Smoking and addiction to paan, gutka, beetle nuts and Naas were found to be important risk factors.
\end{abstract}

Keywords: Colorectal Carcinoma, Retrospective, Incidence.

\section{INTRODUCTION}

Colorectal carcinoma ranks as the third most commonly diagnosed cancer ${ }^{1}$ and fourth cause of cancer causing death worldwide ${ }^{2}$. It is prevalent in older patients with average age at diagnosis about 70 years $^{3}$. Its incidence and mortality both are more in male than females. ${ }^{4}$

Colorectal carcinoma is mainly a disease of developed countries with a rate of 40 per 100,000 people seen in New Zealand, Australia, United States, and Western Europe to less than 5 per 100,000 in Africa and some parts of Asia ${ }^{5}$.

The risk of colorectal carcinoma is higher in individuals with at least one affected firstdegree relative ${ }^{6}$ and in those who are long-term, heavy cigarette smokers ${ }^{7}$. In a study in Egypt agricultural and industrial exposures were found to be associated with an increased risk for colorectal carcinoma ${ }^{8}$. In a study in Europe it was found that the intake of red and processed meat was linked to risk of colorectal carcinoma ${ }^{9}$.

Previous research literature shows that with more than $90 \%$ of patients being diagnosed after age 55 years it was thought of as a disease of older population ${ }^{3}$. However recent research has suggested that there has been an increase in incidence of colorectal carcinoma in young individuals ${ }^{10}$. Hence we are aiming to conduct a retrospective study of the colorectal carcinoma cases documented in the Oncology department of Civil Hospital, Karachi, from 2012-2014 to determine the current patterns of colorectal carcinoma in our setup.

\section{Methodology}

This is a retrospective cohort descriptive hospital based study. It included patients who presented with Colorectal Cancer to the Oncology Department of Civil Hospital, 
Karachi as elective cases from the year January 2012 to December 2014. Civil Hospital, Karachi is a tertiary care hospital which hosts patients from all over Pakistan but primarily from the provinces of Sindh and Baluchistan. All the patients' files from the year 2012 to 2014 were reviewed carefully using a preformed questionnaire. Demographic data of all patients was obtained along with their presenting symptoms and the relevant investigations done. A total of 121 patients were made part of this study based on the inclusion and exclusion criteria. Inclusion criteria was to include all the patients who were diagnosed with Colorectal Carcinoma and had properly maintained records. All the patients who were not diagnosed with Colorectal Carcinoma, all the patients who had similar medical conditions but were not labeled as Colorectal Carcinoma, all such patients whose files or records were not properly managed and patients who were referred to some other hospitals were excluded from the study. The data extracted from the files was entered and computed by Statistical Package for Social Sciences (SPSS) version 20. No personal identifiers were used in any report or publication arising from this study and this study was conducted in accordance with the Ethical principles for medical research involving human subjects of Helsinki Declaration.

\section{Results}

A total of 121 patients were part of this study on the basis of inclusion and exclusion criteria. Out of them $65(53.7 \%)$ were male and $56(46.3 \%)$ were female. Age range was from 14 to 80 years with a mean age \pm SD of $42.4 \pm 16.9$ years. Most of the patients were more than 45 years old as shown in Table1.

Table1. Demographics

\begin{tabular}{|l|c|c|}
\hline & Number of Patients & Percentage \\
\hline Age Range & & \\
\hline$<25$ years & 25 & 20.7 \\
\hline $25-45$ years & 44 & 36.4 \\
\hline$>45$ years & 52 & 43.0 \\
\hline Gender & & \\
\hline Male & 65 & 53.7 \\
\hline Female & 56 & 46.3 \\
\hline Ethnicity & & \\
\hline Urdu & 33 & 27.3 \\
\hline Sindhi & 42 & 34.7 \\
\hline Baluchi & 10 & 8.2 \\
\hline Pashtun & 6 & 5.0 \\
\hline Punjabi & 11 & 9.1 \\
\hline Others & 19 & 15.7 \\
\hline Total & 121 & 100.0 \\
\hline
\end{tabular}

Table 2 shows that one tenth of our patients had a smoking history while twice as that number had addiction to paan, gutka, beetle nuts or naas. $17.4 \%$ of the patients had family history of colorectal carcinoma.

Table2. Risk factors

\begin{tabular}{|l|c|c|}
\hline & $\begin{array}{c}\text { Number } \\
\text { of Patients }\end{array}$ & Percentage \\
\hline Smoking history & 14 & 11.6 \\
\hline Yes & 107 & 88.4 \\
\hline No & & \\
\hline $\begin{array}{l}\text { Addictions (Paan, Gutka, } \\
\text { Beetle nuts, Naas) }\end{array}$ & 28 & 23.1 \\
\hline Yes & 93 & 76.9 \\
\hline No & & \\
\hline $\begin{array}{l}\text { Family history of } \\
\text { colorectal carcinoma }\end{array}$ & 21 & 17.4 \\
\hline Yes & 100 & 82.6 \\
\hline No & 121 & 100.0 \\
\hline Total & &
\end{tabular}

Table3. Presenting complain

\begin{tabular}{|l|c|c|}
\hline Weight loss & $\begin{array}{c}\text { Number of } \\
\text { Patients }\end{array}$ & Percentage \\
\hline Yes & 13 & 10.7 \\
\hline No & 108 & 89.3 \\
\hline Fever & & \\
\hline Yes & 2 & 1.7 \\
\hline No & 119 & 98.3 \\
\hline Fatigue/weakness & & \\
\hline Yes & 0 & 0 \\
\hline No & 121 & 100.0 \\
\hline Bone pain & & \\
\hline Yes & 0 & 0 \\
\hline No & 121 & 100.0 \\
\hline Abdominal pain & & \\
\hline Yes & 16 & 13.2 \\
\hline No & 105 & 86.8 \\
\hline Melena & & \\
\hline Yes & 1 & 0.8 \\
\hline No & 120 & 99.2 \\
\hline Hematochezia & & \\
\hline Yes & 20 & 16.5 \\
\hline No & 101 & 83.5 \\
\hline Diarrhea & & \\
\hline Yes & 118 & 97.5 \\
\hline No & 104 & 86.0 \\
\hline Constipation & 0 & 0 \\
\hline Yes & 121 & 100.0 \\
\hline No & & \\
\hline Tenesmus & & \\
\hline Yes & & \\
\hline No & & \\
\hline & & \\
\hline
\end{tabular}

Table 3 shows the frequency and percentages of the presenting complaint of our patients with colorectal carcinoma to the OPD. Hematochezia was the most common presented complain of these patients. Constipation, abdominal pain and 
weight loss were other common complains in our patients. None of our patients complained of fatigue, bone pain or tenesmus. Only two patients presented with fever, one with melena and three with diarrhea.

\section{DISCUSSION}

Colorectal cancer (CRC) is the third most common cancer worldwide after lung and breast cancers with two-thirds of all colorectal cancers occurring in the more developed regions of the world. ${ }^{11}$ CRC affects men and women of all racial and ethnic groups, and is most often found in people aged 50 years or older in developed countries. ${ }^{12}$ The incidence of CRC in developing countries such as; Pakistan is increasing to an alarming levels and that too in the younger age groups.

In our study, CRC was seen more commonly in people over the age of 45 years, the incidence of CRC in young population that is; less than 45 years is $57.1 \%$ with $20.7 \%$ below the age of 25 . Similar higher incidence was reported by Ahmed et al in Khartoum hospital where 35.4\% of patients were 40 years or less. In this study as well $43.83 \%$ of cancer occurred below age of 50 years. ${ }^{13}$

However, Taha et al in his study in Sudan reported lesser percentage of colorectal cancer in young population (<40 years) of $17.81 \%{ }^{12}$. Another study conducted in Egypt reported that $25 \%$ of colorectal cancers occurred below the age of $40 .^{11}$

Our study also shows that the incidence of colorectal carcinoma in Males is $53.7 \%$ whereas a little lesser incidence of $46.3 \%$ was reported in Females. Hence the ratio of male to female ratio was $1: 1.15$. These findings were supported by another study conducted by Verschueren RC et al and a study conducted in Sudan by Taha et al, where the ratio of male to female were found to be $1: 1.02 .^{12}$

However, Ahmed Gato et al, reported a greater incidence with the male to female ratio of 2.5 : $1 .^{11}$

According to our study, around $42 \%$ of colorectal cancers were reported in Sindhi population, followed by $33 \%$ in Urdu-speaking population. But this could be the result of our tertiary care hospital being located in the province of Sindh, hosting a majority of Sindhi and Urdu-speaking population.
Our study also indicated that $11.6 \%$ of the patients had the history of smoking. The association between cigarette smoking and CRC depends on the number of cigarettes smoked, length of exposure, and age of initiation, which cumulatively yields a risk trajectory over an extended, continuous period. $^{14}$ Limited information is available regarding cigarette smoking in Pakistan hence, any significant conclusion cannot be drawn. About 23.1\% of the patients also had some sort of addictions to Pan, Gutka, beetle nuts and Naas.

In this study, the family history was positive in $17.4 \%$ patients. Near similar findings were reported by Taha et al in his study in Sudan where he reported positive family history in the $15 \%$ of the patients. ${ }^{12}$ Another study conducted by Moris et al in United Kingdom reported that family history accounted for $15.7 \%$ of the population that was made part of the study. ${ }^{15}$

Our study showed that the most common presenting symptom in the patients was Hematochezia (16.5\%) while constipation being the next most common symptom accounting for $14 \%$. Similar results were reported by Payam et al in his study in Iran. ${ }^{16}$ Ahmed gado et al, reported rectal bleeding in $39 \%$ of patients. ${ }^{11}$ However, Taha et al, also reported rectal bleeding to be the most common presenting symptom accounting for $71.7 \%$ and a study conducted in Wad Medani Hospital in Sudan described rectal bleeding as the most common presenting symptom in $97.2 \%$ patients. ${ }^{12}$ In our study however, none of the patients presented with tenesmus as the presenting symptom but in many studies tenesmus was one of the chief complaints in the patients with colorectal carcinoma. A study conducted in Sudan by Taha et al, shows that around $32 \%$ patients had tenesmus. ${ }^{12}$ Abdalla et al however in his study reported that of $35 \%$ of the patients who presented in the emergency department, $94.8 \%$ had an acute or sub acute intestinal obstruction. 13

In conclusion, colorectal cancer was found to affect younger age groups, but with the peak incidence in patients above the age of 45 years. Males were affected more commonly than females. Smoking and addiction to paan, gutka, beetle nuts and Naas were found to be important risk factors, whereas, most common presenting complaint was found to be Hematochezia amongst the patients. 


\section{REFERENCES}

[1] Ferlay, J., Soerjomataram, I., Dikshit, R., Eser, S., Mathers, C., Rebelo, M., ... \& Bray, F. (2015). Cancer incidence and mortality worldwide: sources, methods and major patterns in GLOBOCAN 2012. International journal of cancer, 136(5).

[2] Siegel, R. L., Miller, K. D., \&Jemal, A. (2016). Cancer statistics, 2016. CA: a cancer journal for clinicians, 66(1), 7-30.

[3] Atkin, W. S., Northover, J. M. A., Cuzick, J., \&Whynes, D. K. (1993). Prevention of colorectal cancer by once-only sigmoidoscopy. The Lancet, 341(8847), 736740 .

[4] Siegel, R. L., Miller, K. D., Fedewa, S. A., Ahnen, D. J., Meester, R. G., Barzi, A., \&Jemal, A. (2017). Colorectal cancer statistics, 2017. CA: a cancer journal for clinicians, 67(3), 177-193.

[5] World Cancer Research Fund, \& American Institute for Cancer Research. (2007). Food, nutrition, physical activity, and the prevention of cancer: a global perspective (Vol. 1). AmerInst for Cancer Research.

[6] Butterworth, A. S., Higgins, J. P., \&Pharoah, P. (2006). Relative and absolute risk of colorectal cancer for individuals with a family history: a meta-analysis. European journal of cancer, 42(2), 216-227.

[7] Giovannucci, E. (2001). An updated review of the epidemiological evidence that cigarette smoking increases risk of colorectal cancer. Cancer Epidemiology and Prevention Biomarkers, 10(7), 725-731.

[8] Lo, A. C., Soliman, A. S., Khaled, H. M., Aboelyazid, A., \&Greenson, J. K. (2010). Lifestyle, occupational, and reproductive factors and risk of colorectal cancer. Diseases of the Colon and Rectum, 53(5), 830.
[9] Norat, T., Bingham, S., Ferrari, P., Slimani, N., Jenab, M., Mazuir, M., ...\&Boutron-Ruault, M. C. (2005). Meat, fish, and colorectal cancer risk: the European Prospective Investigation into cancer and nutrition. Journal of the national cancer institute, 97(12), 906-916.

[10] O'Connell, J. B., Maggard, M. A., Liu, J. H., \&Etzioni, D. A. (2003). Rates of colon and rectal cancers are increasing in young adults. The American surgeon, 69(10), 866.

[11] Gado, A., Ebeid, B., Abdelmohsen, A., \& Axon, A. (2014). Colorectal cancer in Egypt is commoner in young people: Is this cause for alarm?.Alexandria Journal of Medicine, 50(3), 197-201

[12] Mohamed, O. A. T., Ahmed, A. E. A., \&Roa, S. M. (2015). Pattern \& presentation of colorectal cancer in central Sudan, a retrospective descriptive study, 2010-2012. African health sciences, 15(2), 576-580.

[13] Abdalla, A. A., Musa, M. T., \&Khair, R. Z. (2007). Presentation of colorectal cancer in Khartoum teaching hospital. Sudan JMS, 2(4).

[14] Katalambula, L. K., Ntwenya, J. E., Ngoma, T., Buza, J., Mpolya, E., Mtumwa, A. H., \&Petrucka, P. (2016). Pattern and Distribution of Colorectal Cancer in Tanzania: A Retrospective Chart Audit at Two National Hospitals. Journal of cancer epidemiology, 2016

[15] Morris, E. J. A., Penegar, S., Whitehouse, L. E., Quirke, P., Finan, P., Bishop, D. T., ...\&Houlston, R. S. (2013). A retrospective observational study of the relationship between family history and survival from colorectal cancer. British journal of cancer, 108(7), 15021507.

[16] Pahlavan, P. S., \&Kanthan, R. (2006). The epidemiology and clinical findings of colorectal cancer in Iran. Women, 86(43.0), 11.

Citation: Tooba Irfan, Amara Zafar, Muhammad Yusuf Hafiz, Current Patterns of Colorectal Carcinoma: Retrospective Evaluation of Cases. ARC Journal of Cancer Science 2018; 4(2): 14-17. DOI:http://dx.doi.org/10.20431/2455-6009.0402004

Copyright: (c) 2018 Authors. This is an open-access article distributed under the terms of the Creative Commons Attribution License, which permits unrestricted use, distribution, and reproduction in any medium, provided the original author and source are credited. 